\title{
Chapter 1 \\ Examination of the Correlation Between \\ Tectonic Landforms and Shallow Subsurface \\ Structural Datasets for the Estimation of Seismic Source Faults
}

\author{
Takashi Kumamoto, Masatoshi Fujita, Hideaki Goto, and Takashi Nakata
}

\begin{abstract}
Estimation of the magnitudes of future earthquakes produced by faults is critical in seismic hazard assessment, especially for faults that are short in extent compared with the thickness of the seismogenic layers of the upper crust. A new seismogenic fault model for earthquake size estimation was constructed by combining (a) new assessments of the precise location and distribution of active faults from aerial photograph analysis and (b) estimations of subsurface structures from geological, gravity, and seismicity datasets. The integrated results of (1) tectonic landforms determined from aerial photographs, (2) geologic data showing the distribution of geologic faults, (3) Bouguer gravity anomaly data over wavelengths of 4-200 km, and (4) seismicity data were superimposed on geographic information system (GIS) data around the nuclear power plants in Japan. The results indicate the possible occurrence of large earthquakes, because the lengths of the subsurface earthquake faults were estimated to be longer than the length of the surface faults if subsurface structures were included.
\end{abstract}

Keywords Aerial photograph analysis - Distribution of active faults - Subsurface structure

T. Kumamoto $(\bowtie)$

Okayama University, Fact. Science, Tsushimanaka 3-1-1, Kita-ku, Okayama 700-8530, Japan e-mail: tkuma@cc.okayama-u.ac.jp

M. Fujita

Nuclear Regulation Authority, Roppongi 1-9-9, Minato-ku, Tokyo 106-8450, Japan

H. Goto • T. Nakata

Hiroshima University, Fact. Letter, Kagamiyama 1-3-2, Higashi-Hiroshima 739-8511, Japan

K. Kamae (ed.), Earthquakes, Tsunamis and Nuclear Risks,

DOI 10.1007/978-4-431-55822-4_1 


\subsection{Introduction}

The Headquarters for Earthquake Research Promotion (HERP) published the "Method of long-term evaluation of active fault (preliminary version)" (HERP [1]), a new integrated method of active fault assessment for seismic hazard analysis. Several problems were highlighted in this report, with two being of particular importance. First, the surface ruptures of some recent intraplate earthquakes in Japan were shorter than the source fault of the earthquake in the subsurface. Second, it is necessary to update Matsuda's " $5 \mathrm{~km}$ rule" [2], the current reference criterion of fault gap distance for assessing if neighboring faults rupture simultaneously, which is widely used for seismic hazard analysis in Japan.

The HERP [1] also included some ideas for improvement and methods to solve the problem of the mismatch between surface and subsurface fault lengths for moderate to large earthquakes. One example is to incorporate subsurface structural datasets such as geologic maps, gravity anomaly data, and instrumentally observed seismicity data with the surface distribution of active faults deduced from aerial photograph analysis to better estimate subsurface earthquake source faults.

Preliminary results of the new method of comparing surface and subsurface structures are outlined here, especially for the areas near nuclear power plants in Japan. We conducted aerial photograph analysis to identify tectonic landforms and created fault distribution maps. Datasets representing subsurface structures in the study areas were overlain on the maps using geographic information system (GIS) techniques. We then estimated (a) the length of earthquake source fault for isolated faults with short surface lengths and (b) the possibility that neighboring surface faults would rupture simultaneously due to subsurface continuity.

\subsection{Data}

The reference criteria and legends for the aerial photograph analysis in this study are the same as those in the "Active Fault Map in Urban Area" published by the Geospatial Information Authority of Japan [3], and cross-check rule is also applied for the analysis. The top section of Fig. 1.1 (1)-(14) shows the distribution of active faults in the study areas determined by aerial photograph analysis. The rectangles in each section indicate a second-order map grid (scale 1:25,000) from the Geospatial Information Authority of Japan and show the areas of detailed aerial photograph analysis in this study. The numbers of the top sections in Fig. 1.1 indicate the corresponding identification in Table 1.1. The middle left section shows the distribution of "Active faults in Japan" (RGAF [4]), and the middle right section shows the distribution in the "Digital Active Fault Map of Japan" (Nakata and Imaizumi ed. [5]) for comparison. As the same criterion was used for the "Digital Active Fault Map of Japan" and this study, there is little difference in the results.

A total of 249 active faults were identified in this study (Table 1.1), with 78 of these partially or completely corresponding to faults identified in "Active faults in Japan" (RGAF [4]). Among the remaining 171 faults, 164 were $10 \mathrm{~km}$ or shorter in 
(1) Tomari
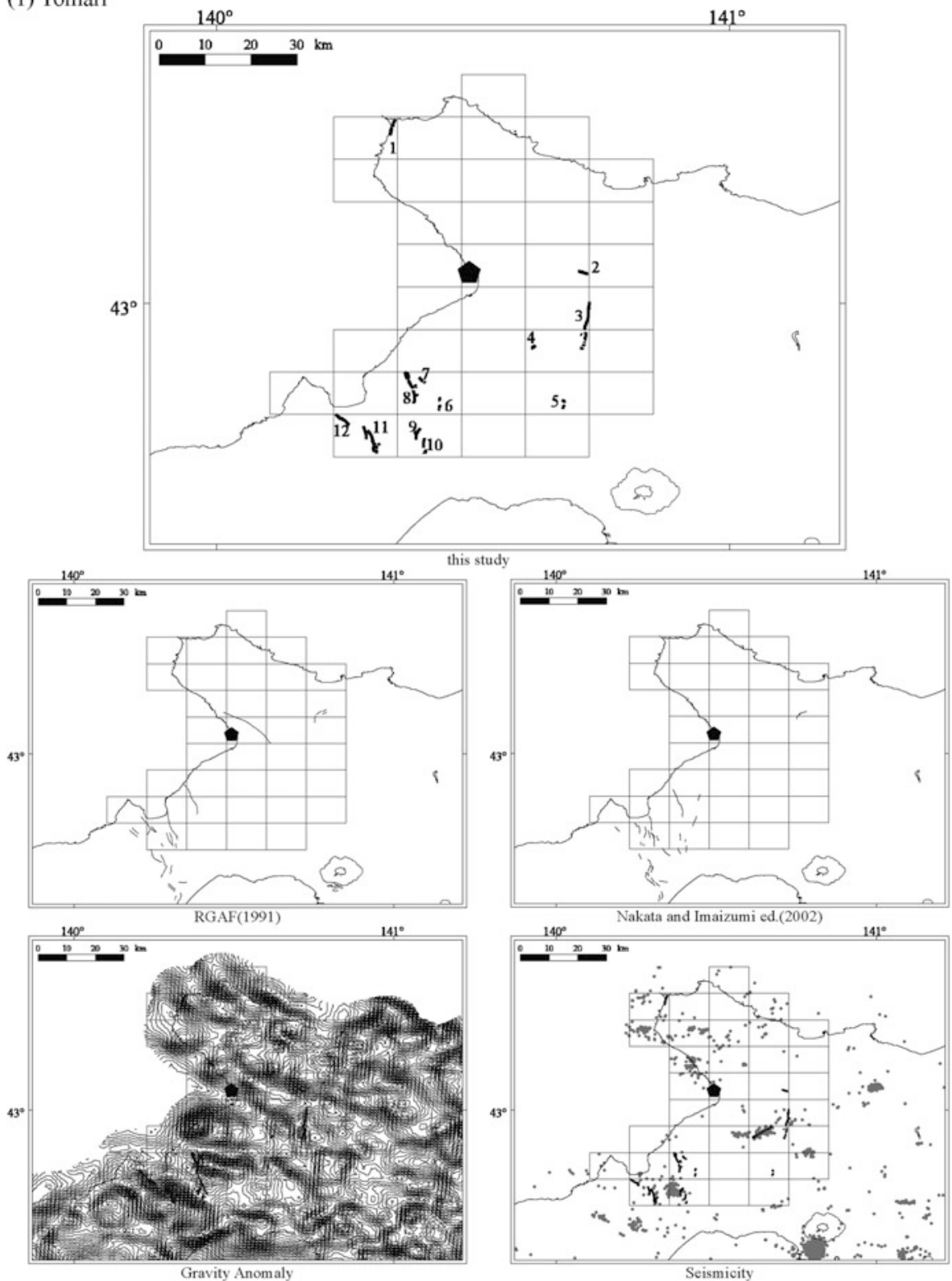

Fig. 1.1 (continued) 
(2) Oma
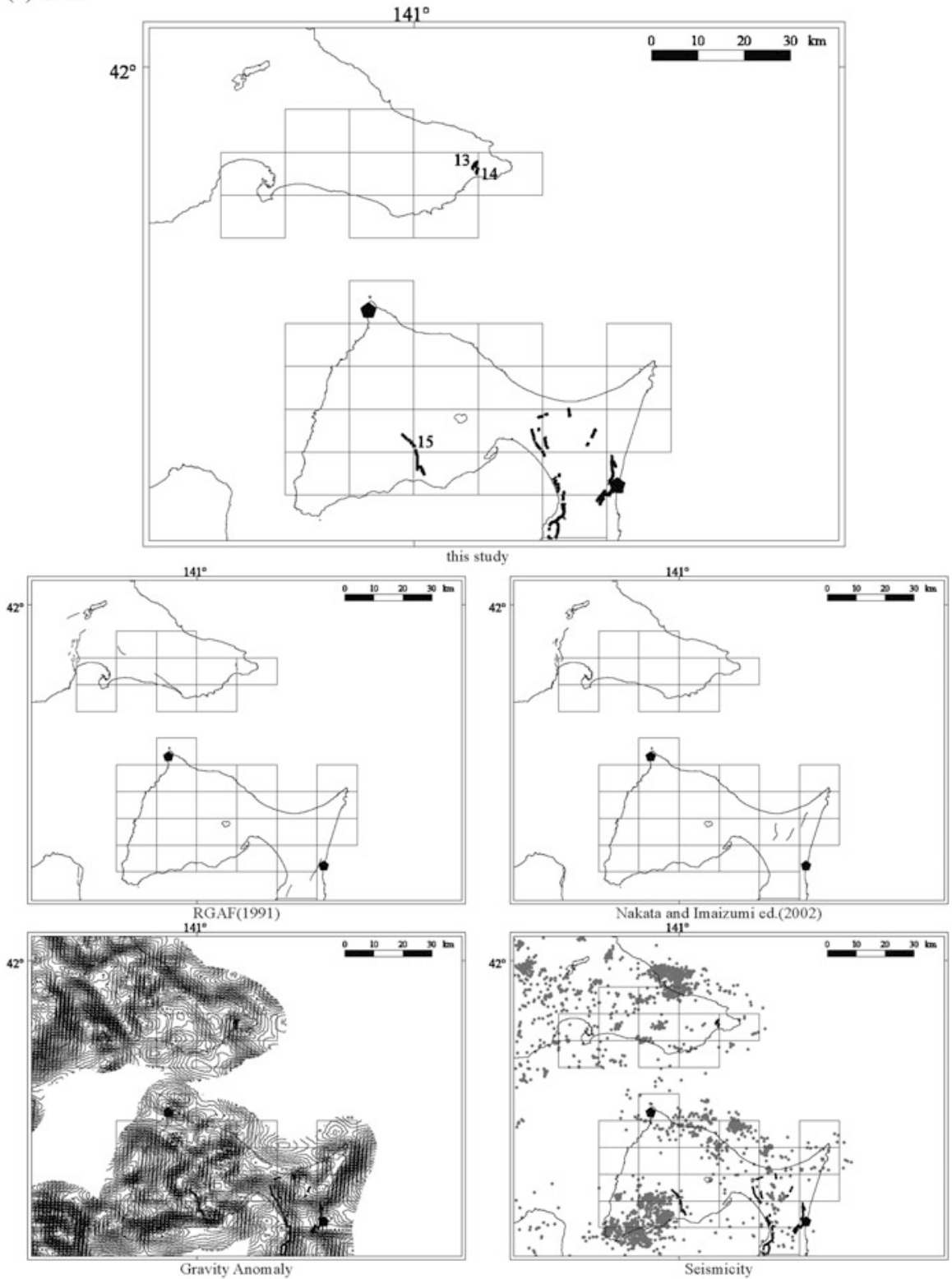

Fig. 1.1 (continued) 
(3) Higashidori
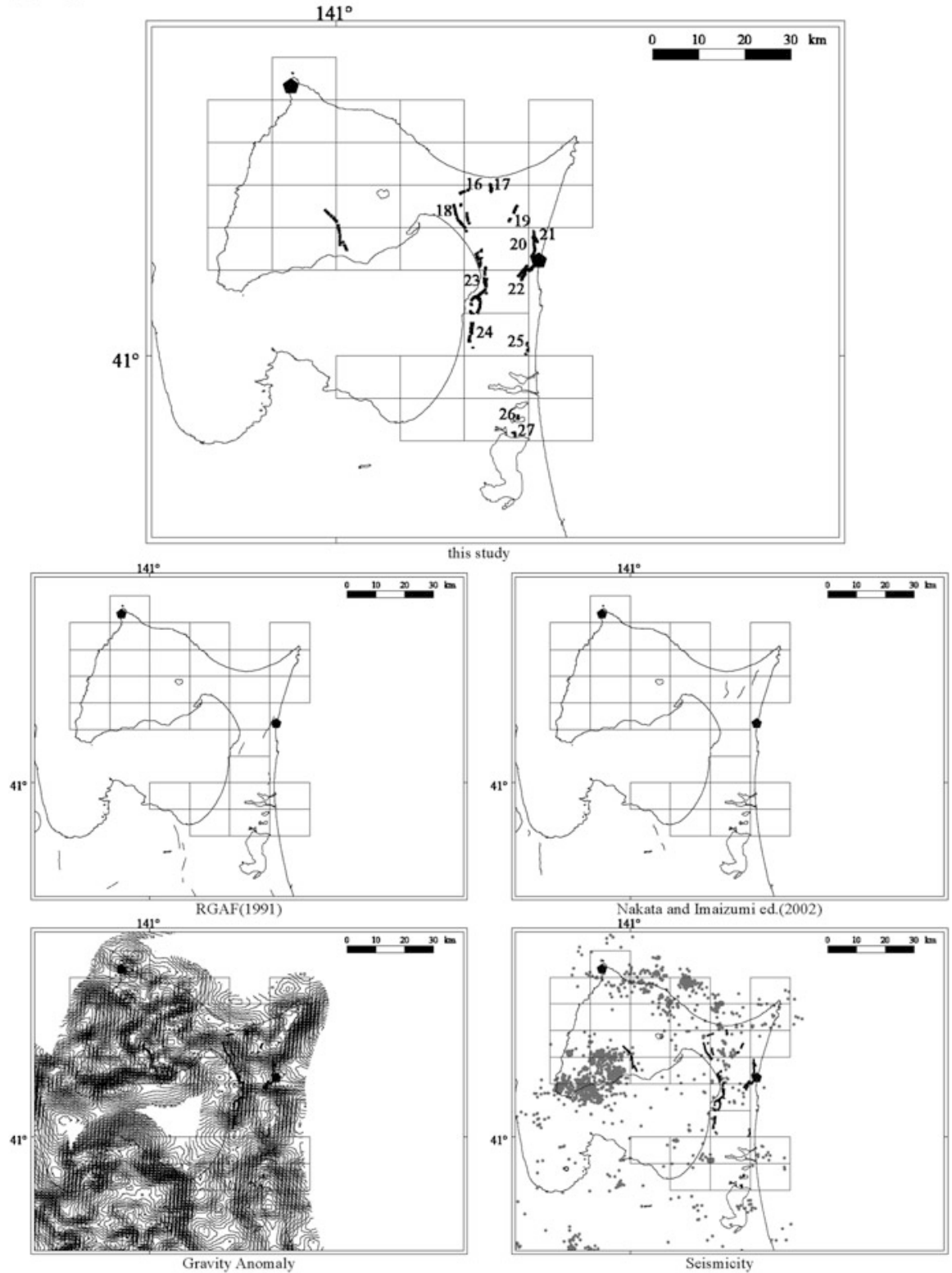

Fig. 1.1 (continued) 
(4) Onagawa
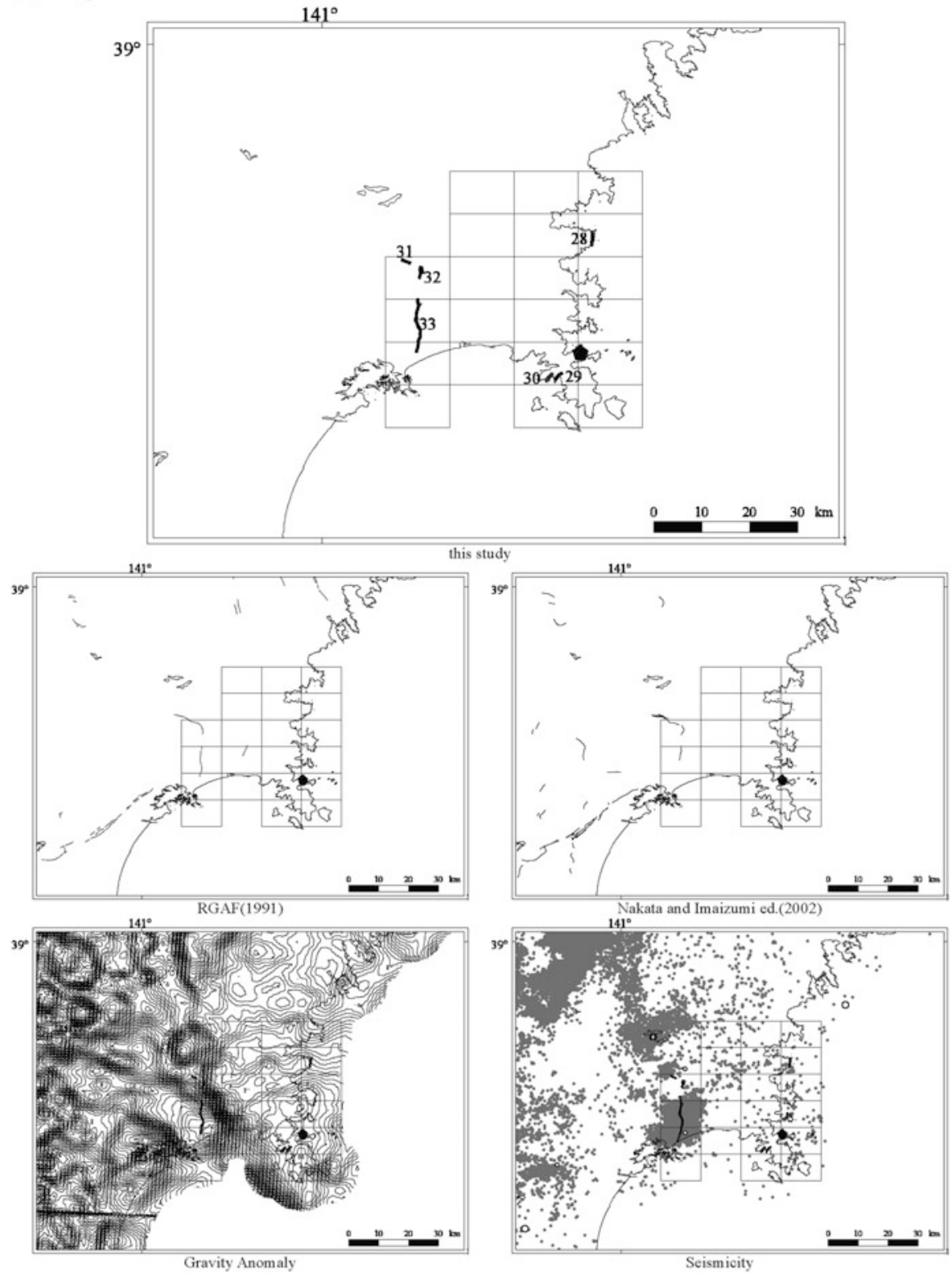

$\mathrm{Nak}$

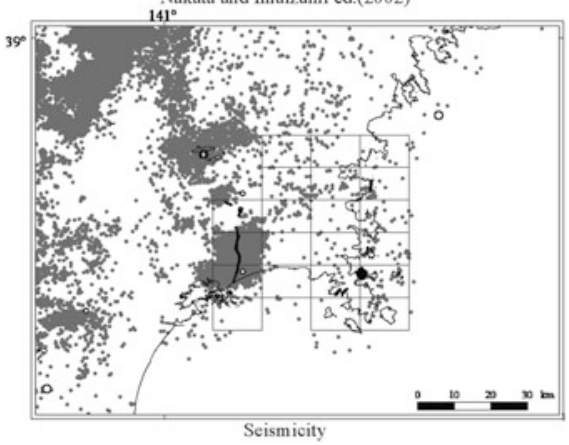

Fig. 1.1 (continued) 
(5) Fukushima

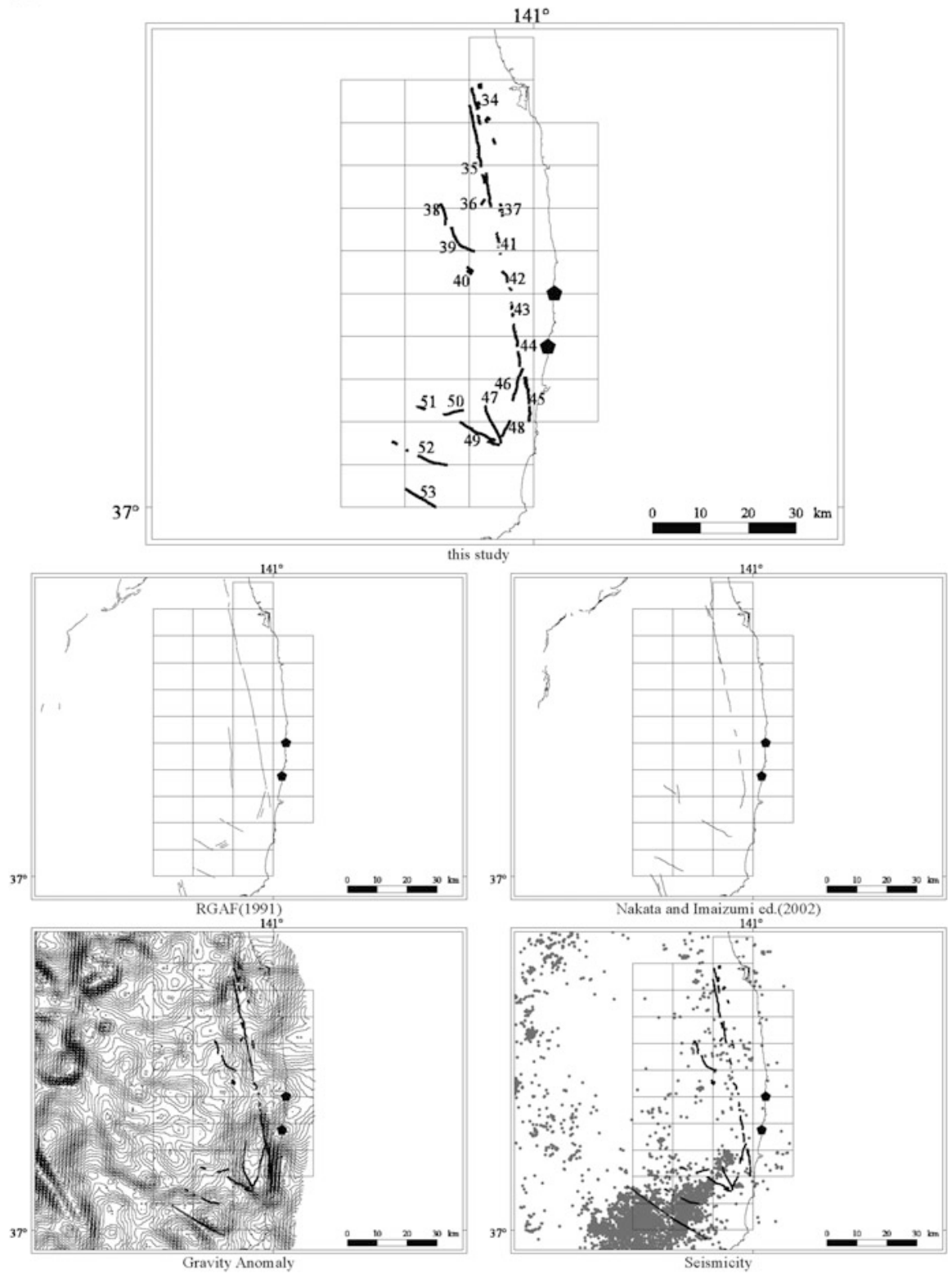

Fig. 1.1 (continued) 
(6) Tokai
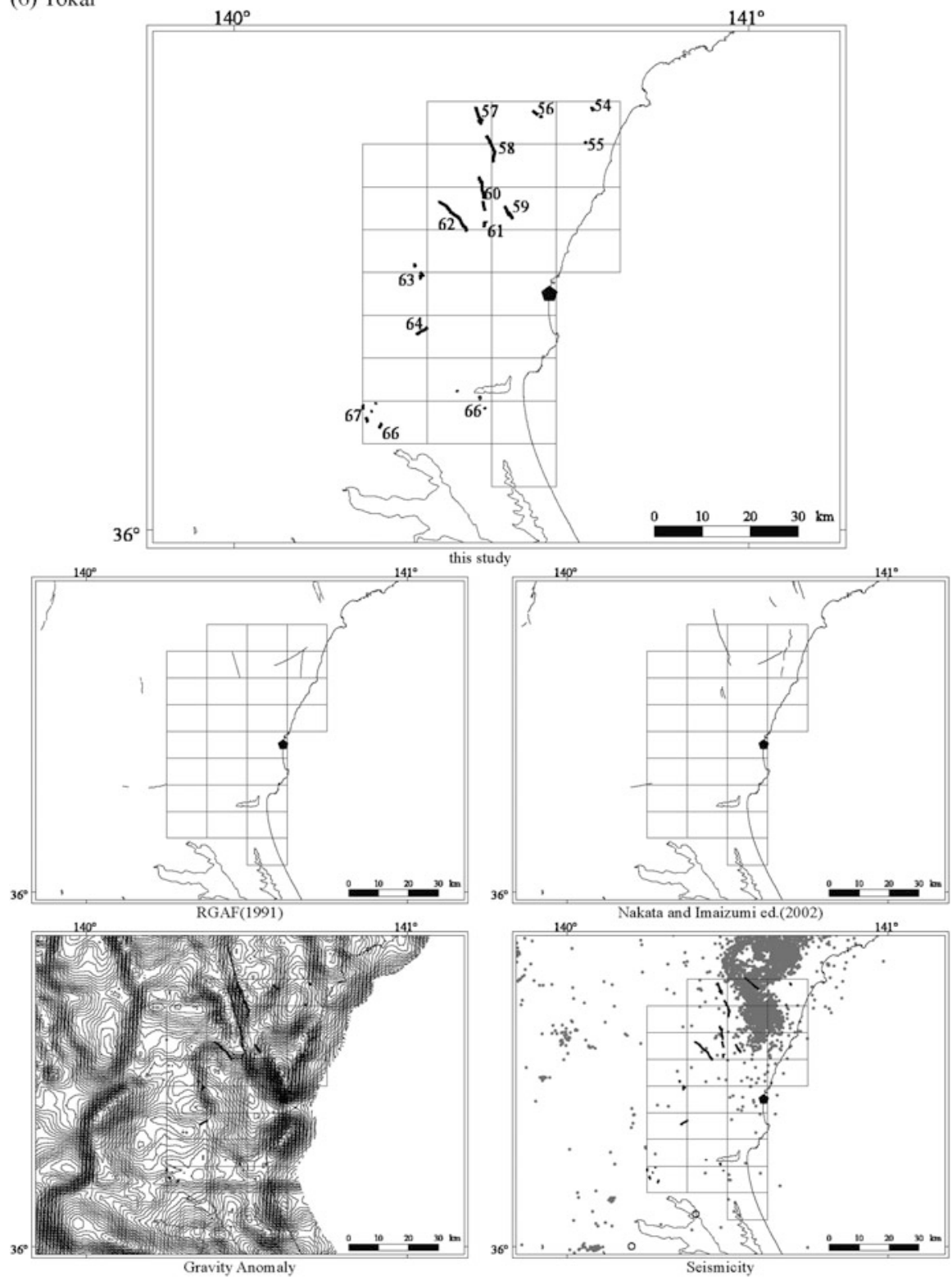

Fig. 1.1 (continued) 
1 Examination of the Correlation Between Tectonic Landforms and Shallow...

(7) Kashiwazaki
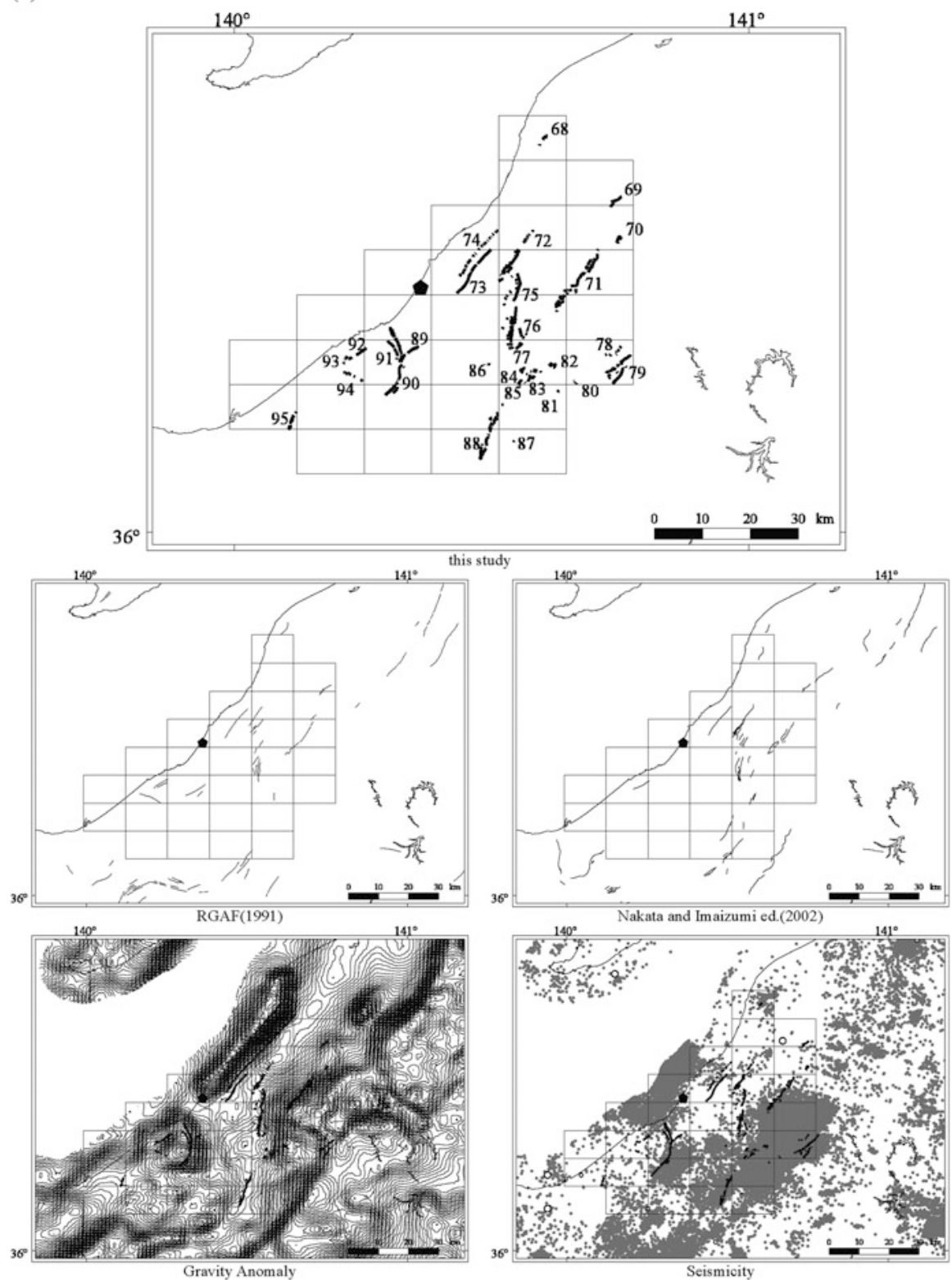

Fig. 1.1 (continued) 
(8) Hamaoka

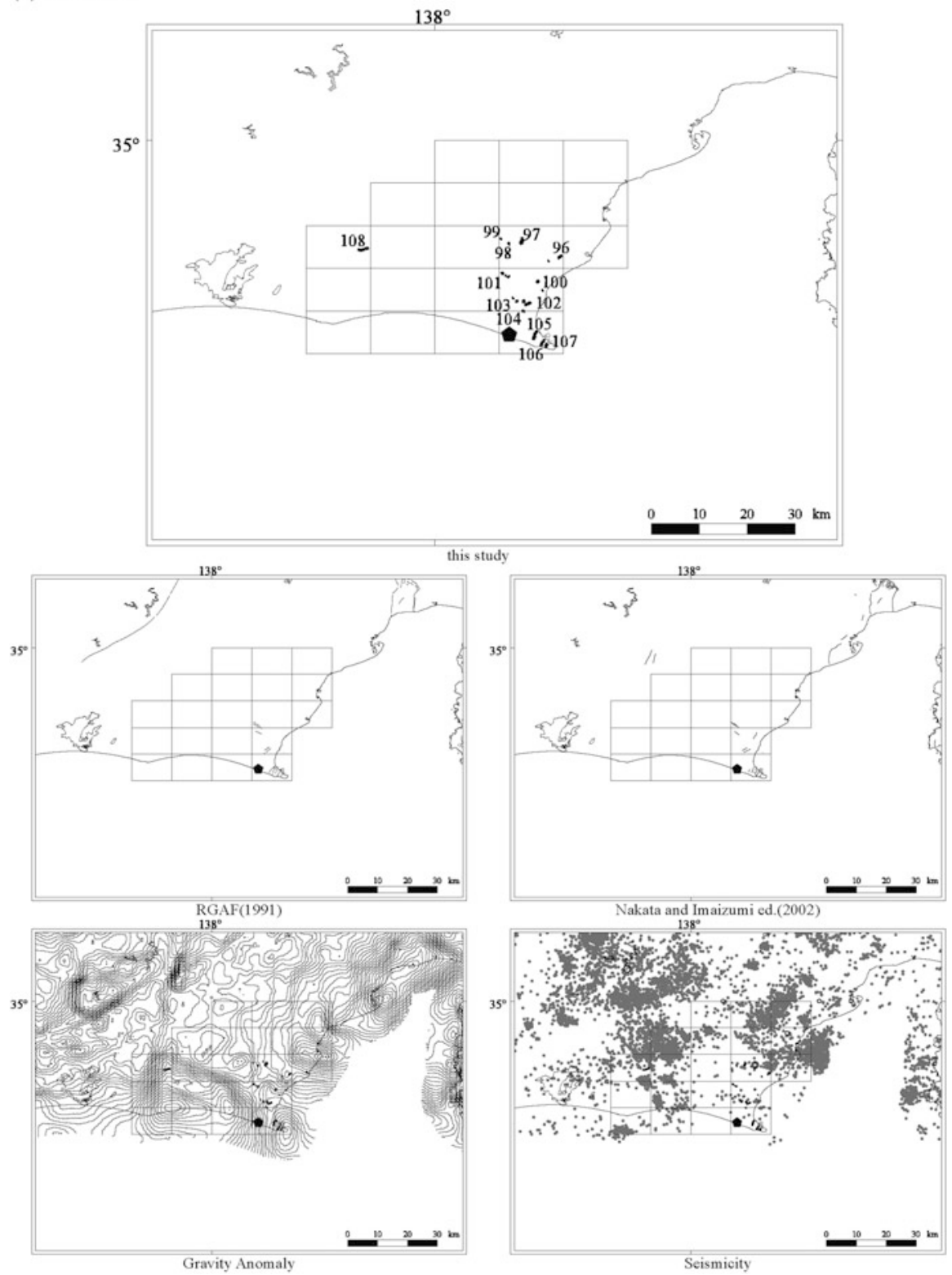

Fig. 1.1 (continued) 
(9) Shika

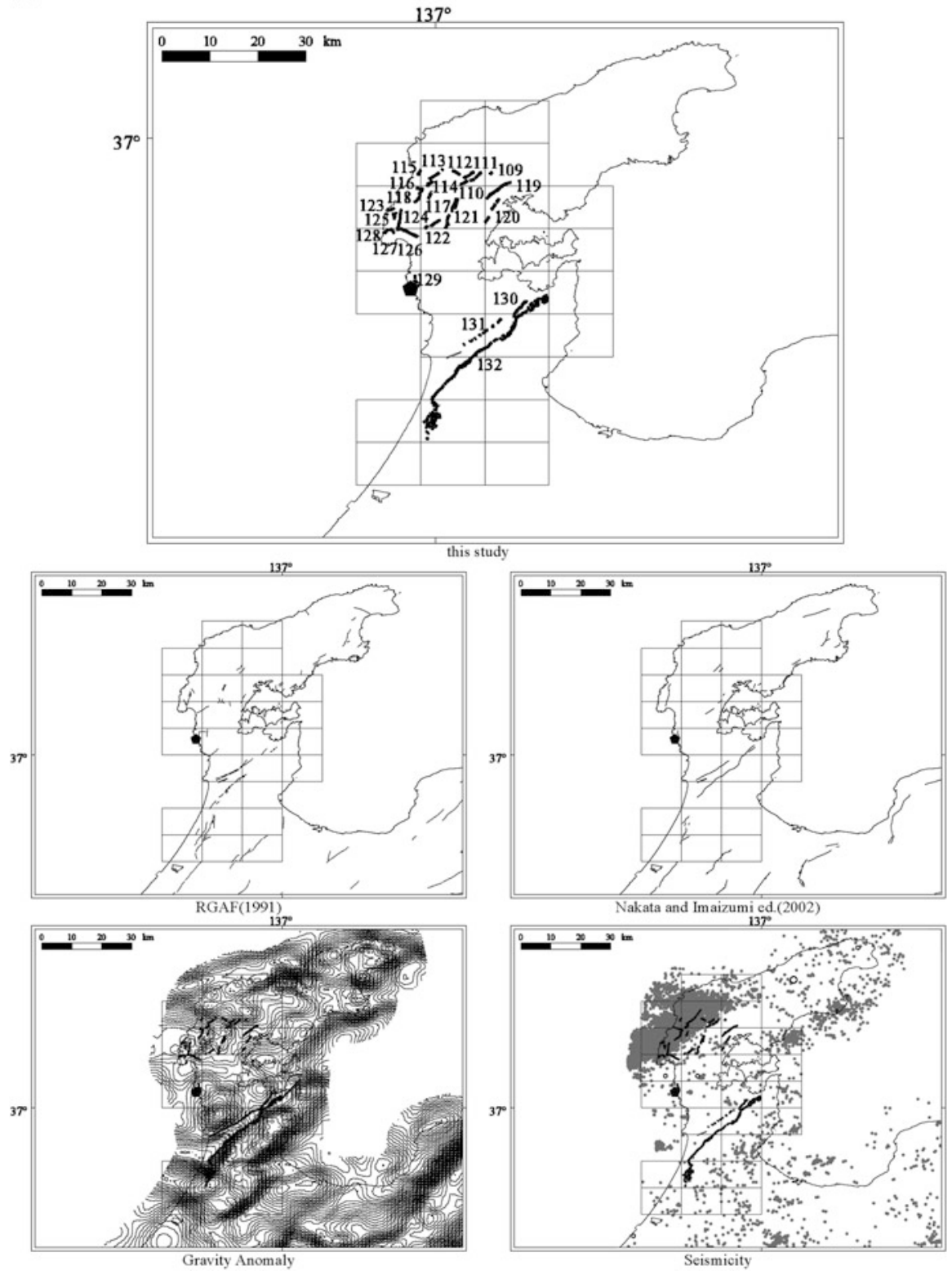

Fig. 1.1 (continued) 
(10) Tsuruga

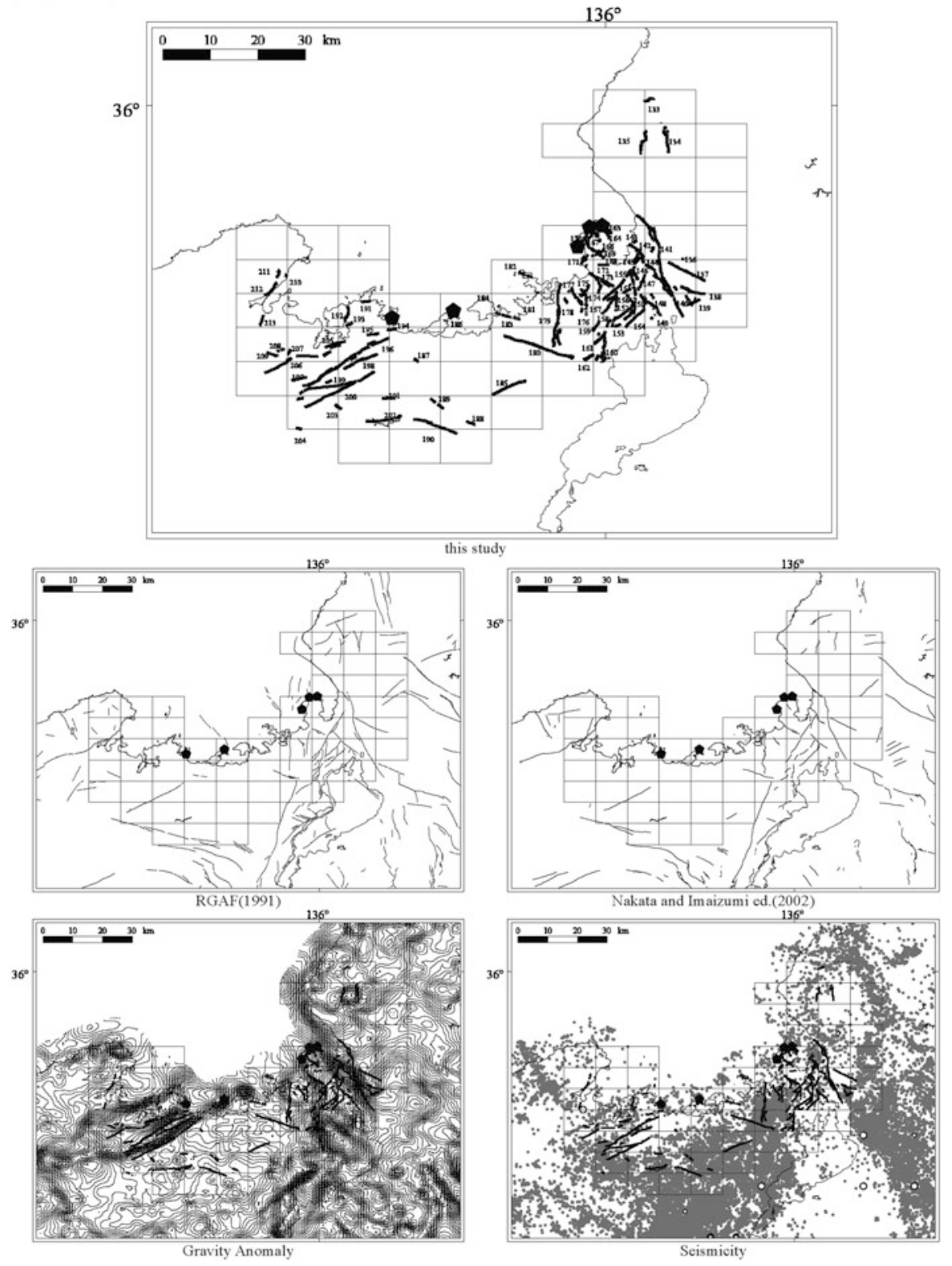

Fig. 1.1 (continued) 
(11) Shimane

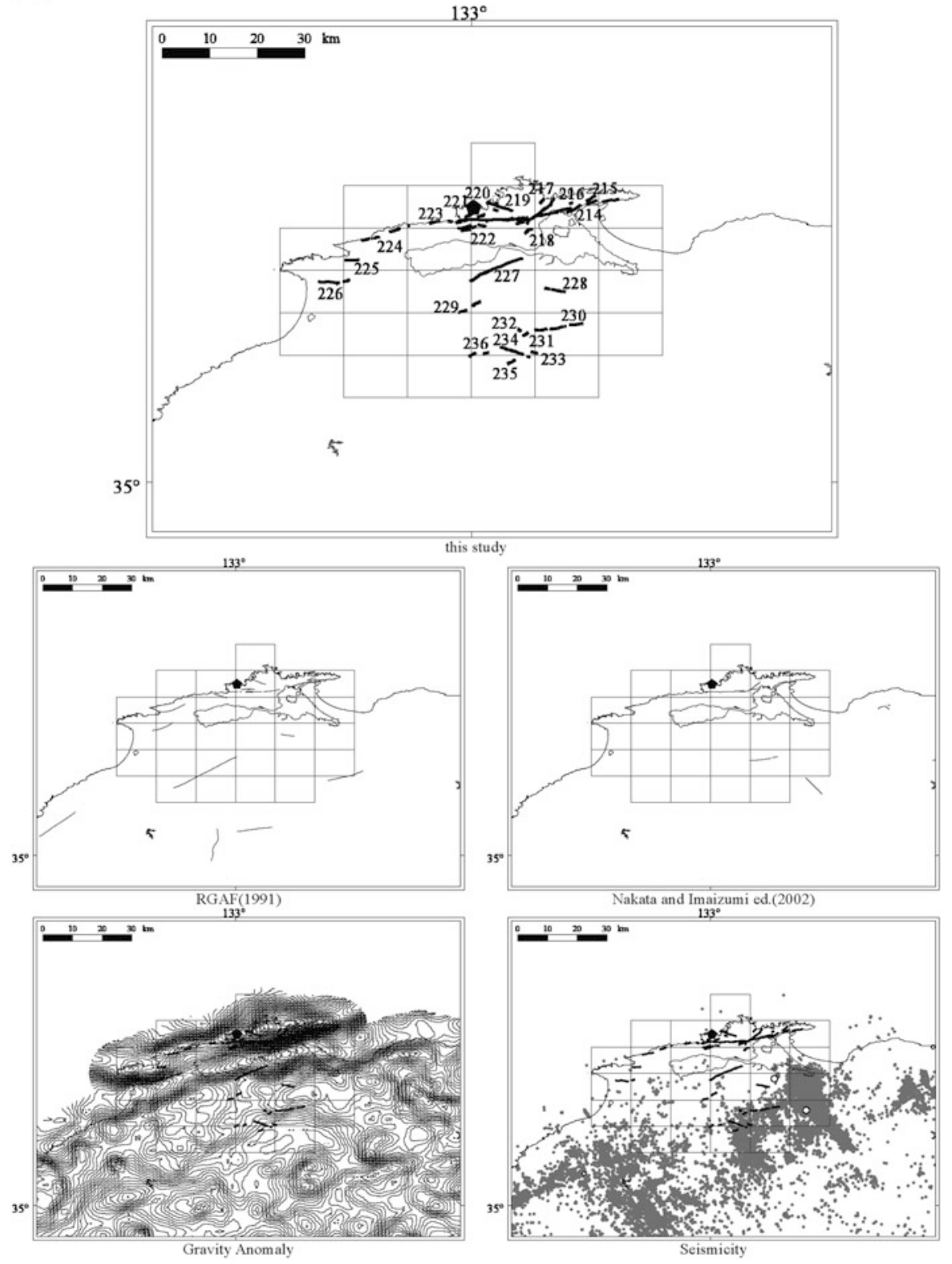

Fig. 1.1 (continued) 
(12) Ikata

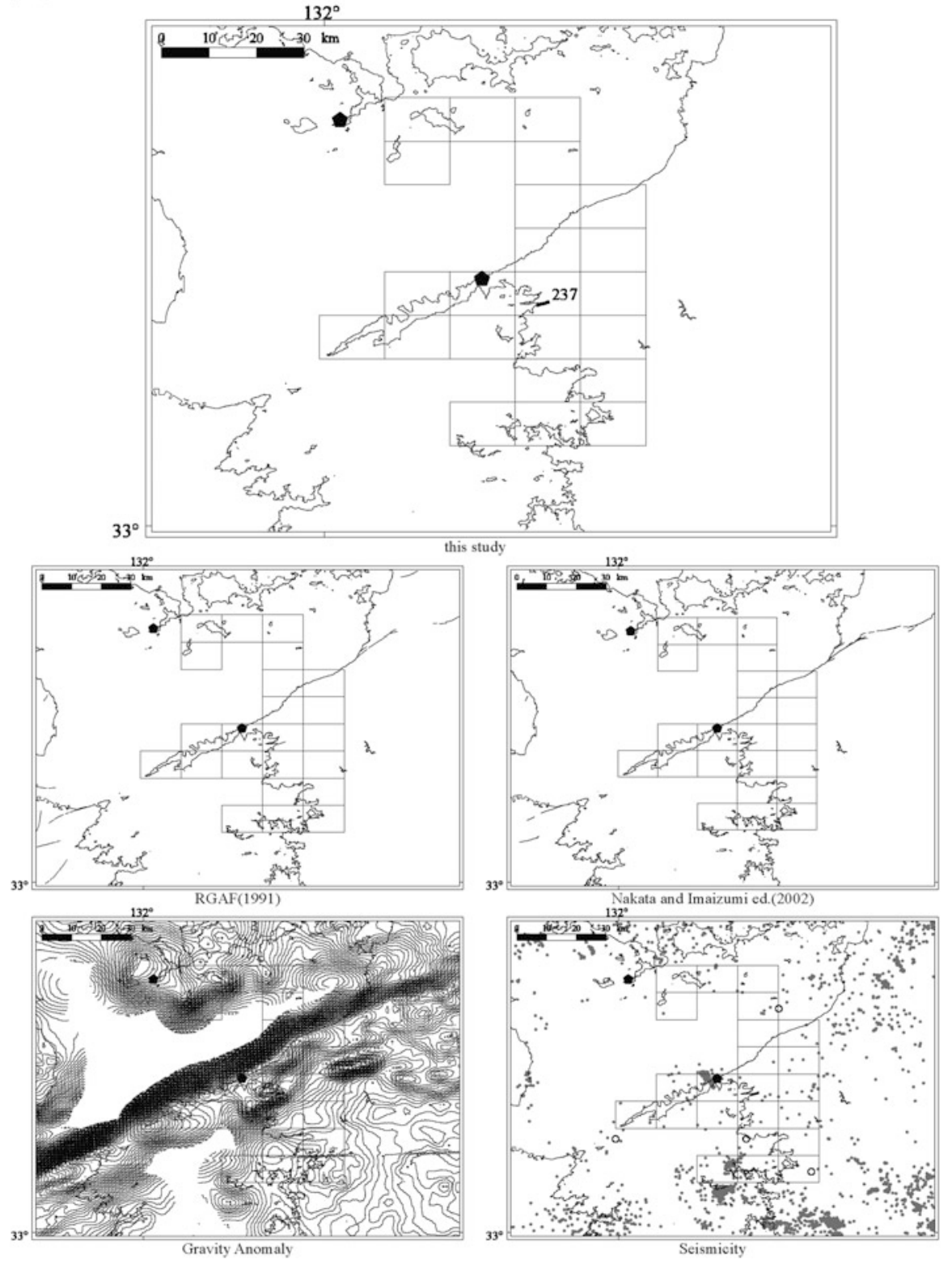

Fig. 1.1 (continued) 
(13) Genkai

$141^{\circ}$

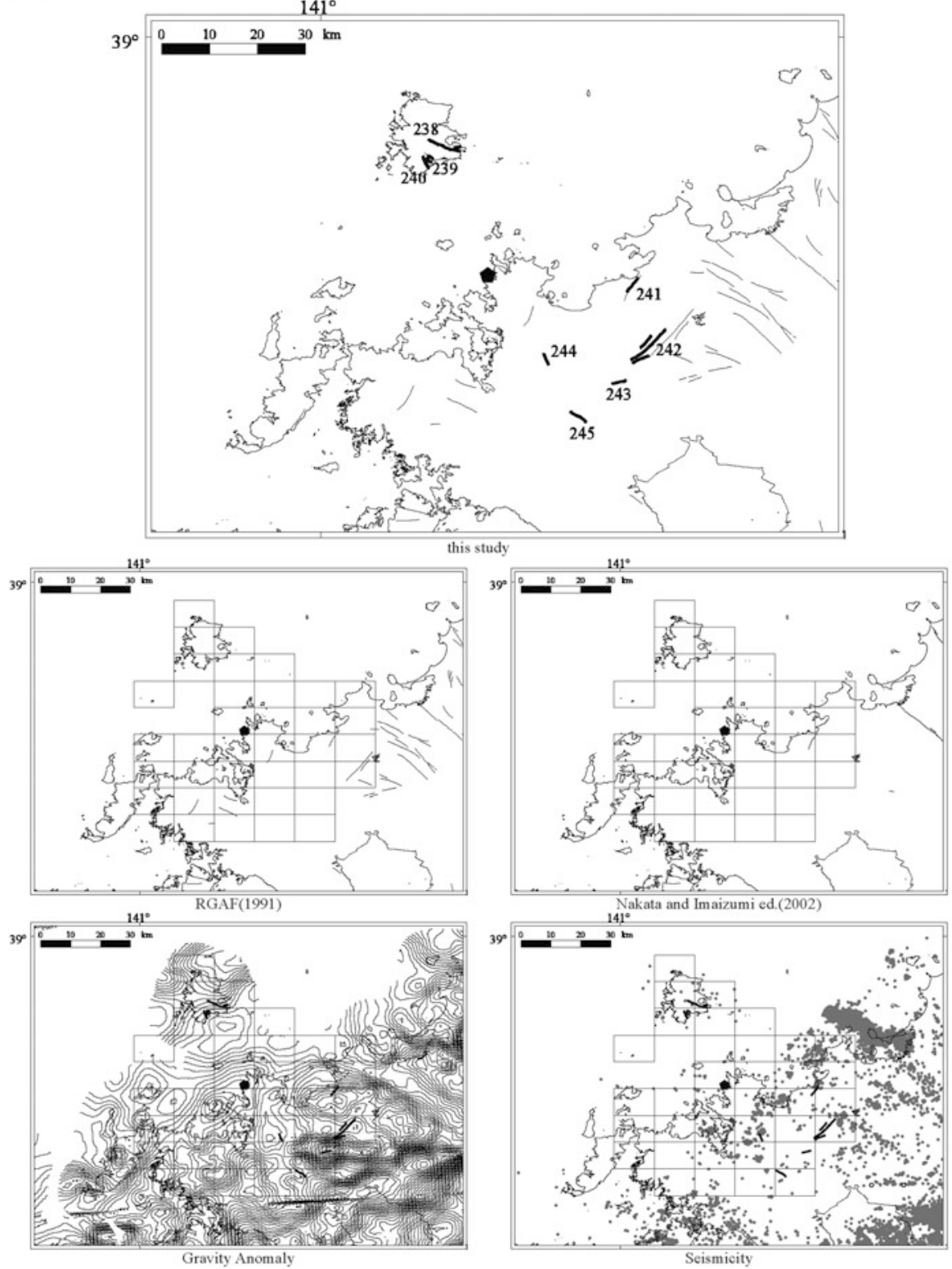

Fig. 1.1 (continued) 
(14) Sendai
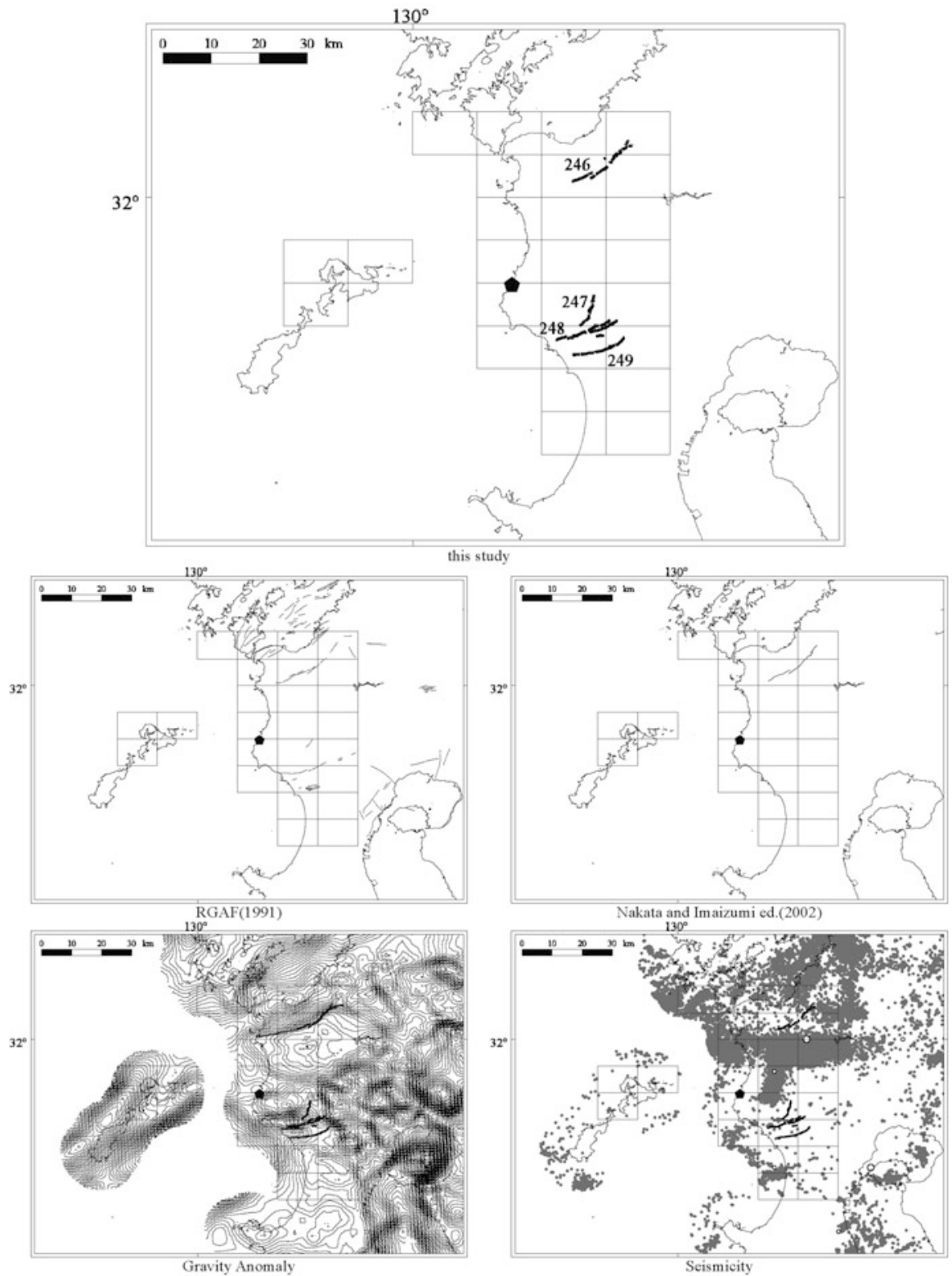

Fig. 1.1 Distribution of active faults (top: this study, middle left: RGAF (1991), middle right (Nakata and Imaizumi [5])) and subsurface datasets (bottom left: 1 mgal contour of Bouguer gravity anomaly, bottom right: observed seismicity) of 14 subjected areas 
1 Examination of the Correlation Between Tectonic Landforms and Shallow...

Table 1.1 Surface and subsurface fault length in Fig. 1.1 and Fig. 1.2

\begin{tabular}{|c|c|c|c|c|c|c|}
\hline Site & ID & This study & RGAF (1991) & Geology & Gravity & Seismicity \\
\hline Tomari & 1 & 3.6 & - & 5.0 & - & - \\
\hline Tomari & 2 & 1.7 & - & 3.4 & - & - \\
\hline Tomari & 3 & 8.8 & - & 14.4 & 14.4 & - \\
\hline Tomari & 4 & 0.9 & - & - & - & 6.3 \\
\hline Tomari & 5 & 1.3 & - & - & - & - \\
\hline Tomari & 6 & 1.6 & - & 3.5 & - & - \\
\hline Tomari & 7 & 1.3 & - & - & - & - \\
\hline Tomari & 8 & 6.4 & 12.0 & - & 15.5 & - \\
\hline Tomari & 9 & 2.6 & - & 5.7 & - & - \\
\hline Tomari & 10 & 2.5 & - & - & - & - \\
\hline Tomari & 11 & 4.7 & 6.0 & - & - & - \\
\hline Tomari & 12 & 3.2 & 6.0 & 4.7 & 7.1 & - \\
\hline Oma & 13 & 1.6 & 3.0 & - & - & - \\
\hline Oma & 14 & 1.2 & 3.0 & 3.5 & 3.5 & - \\
\hline Oma & 15 & 7.6 & - & 10.8 & - & - \\
\hline Higashidori & 16 & 1.7 & - & - & - & - \\
\hline Higashidori & 17 & 2.0 & - & - & - & - \\
\hline Higashidori & 18 & 5.6 & - & 25.6 & 26.7 & - \\
\hline Higashidori & 19 & 2.7 & - & - & - & - \\
\hline Higashidori & 20 & 6.1 & - & - & - & - \\
\hline Higashidori & 21 & 1.5 & - & - & - & - \\
\hline Higashidori & 22 & 3.9 & 7.0 & - & - & - \\
\hline Higashidori & 23 & 9.9 & 4.0 & 25.6 & 26.7 & - \\
\hline Higashidori & 24 & 3.9 & - & - & - & - \\
\hline Higashidori & 25 & 1.5 & 4.0 & 4.1 & - & - \\
\hline Higashidori & 26 & 1.0 & - & - & - & - \\
\hline Higashidori & 27 & 1.2 & - & - & - & - \\
\hline Onagawa & 28 & 3.2 & - & - & - & - \\
\hline Onagawa & 29 & 2.1 & - & 4.4 & - & - \\
\hline Onagawa & 30 & 2.0 & - & - & - & - \\
\hline Onagawa & 31 & 1.8 & 12.0 & 5.6 & - & - \\
\hline Onagawa & 32 & 2.8 & 12.0 & 8.5 & 8.5 & - \\
\hline Onagawa & 33 & 12.3 & 8.0 & 12.5 & - & 16.5 \\
\hline Fukushima & 34 & 7.3 & - & 12.7 & - & - \\
\hline Fukushima & 35 & 20.3 & 55.0 & 67.5 & 36.1 & - \\
\hline Fukushima & 36 & 1.5 & - & - & - & - \\
\hline Fukushima & 37 & 1.7 & - & - & - & - \\
\hline Fukushima & 38 & 4.9 & - & - & - & - \\
\hline Fukushima & 39 & 7.1 & - & - & - & - \\
\hline Fukushima & 40 & 1.7 & - & - & - & - \\
\hline Fukushima & 41 & 2.1 & 55.0 & 67.5 & 36.1 & - \\
\hline Fukushima & 42 & 3.3 & 55.0 & 67.5 & - & - \\
\hline
\end{tabular}


Table 1.1 (continued)

\begin{tabular}{|c|c|c|c|c|c|c|}
\hline Site & ID & This study & RGAF (1991) & Geology & Gravity & Seismicity \\
\hline Fukushima & 43 & 1.6 & 55.0 & 67.5 & - & - \\
\hline Fukushima & 44 & 8.1 & 55.0 & 67.5 & 25.8 & - \\
\hline Fukushima & 45 & 8.3 & 15.0 & 13.5 & 16.9 & - \\
\hline Fukushima & 46 & 9.1 & 10.0 & 67.5 & 25.8 & - \\
\hline Fukushima & 47 & 3.6 & - & - & 25.8 & - \\
\hline Fukushima & 48 & 8.7 & - & - & 17.9 & - \\
\hline Fukushima & 49 & 7.6 & 6.0 & 8.0 & - & - \\
\hline Fukushima & 50 & 3.6 & - & - & - & - \\
\hline Fukushima & 51 & 1.3 & - & - & - & - \\
\hline Fukushima & 52 & 7.0 & 5.0 & 19.3 & - & - \\
\hline Fukushima & 53 & 6.8 & 6.0 & 16.9 & 18.2 & 28.9 \\
\hline Tokai & 54 & 0.9 & - & - & - & - \\
\hline Tokai & 55 & 0.5 & 10.0 & - & - & - \\
\hline Tokai & 56 & 1.8 & - & - & - & 5.6 \\
\hline Tokai & 57 & 3.0 & - & - & 26.0 & - \\
\hline Tokai & 58 & 6.0 & - & - & 26.0 & - \\
\hline Tokai & 59 & 3.2 & - & - & - & - \\
\hline Tokai & 60 & 6.8 & 7.0 & 11.7 & 23.9 & - \\
\hline Tokai & 61 & 1.1 & - & - & - & - \\
\hline Tokai & 62 & 8.4 & - & 12.1 & - & - \\
\hline Tokai & 63 & 1.7 & - & - & - & - \\
\hline Tokai & 64 & 2.2 & - & 10.3 & - & - \\
\hline Tokai & 65 & 0.6 & - & - & - & - \\
\hline Tokai & 66 & 1.1 & - & - & - & - \\
\hline Tokai & 67 & 2.0 & - & - & - & - \\
\hline Kashiwazaki & 68 & 0.8 & - & - & 12.6 & - \\
\hline Kashiwazaki & 69 & 2.1 & 4.0 & 3.2 & - & - \\
\hline Kashiwazaki & 70 & 1.5 & - & - & - & - \\
\hline Kashiwazaki & 71 & 11.3 & 15.0 & 16.8 & - & - \\
\hline Kashiwazaki & 72 & 6.4 & 5.0 & 14.5 & - & - \\
\hline Kashiwazaki & 73 & 10.0 & - & 14.4 & - & - \\
\hline Kashiwazaki & 74 & 5.0 & 11.0 & 13.3 & 31.8 & - \\
\hline Kashiwazaki & 75 & 11.5 & 7.0 & 16.2 & 16.2 & - \\
\hline Kashiwazaki & 76 & 1.8 & - & - & - & - \\
\hline Kashiwazaki & 77 & 1.5 & - & - & - & - \\
\hline Kashiwazaki & 78 & 1.0 & - & - & - & - \\
\hline Kashiwazaki & 79 & 4.6 & - & 9.0 & - & 9.6 \\
\hline Kashiwazaki & 80 & 0.3 & - & - & - & - \\
\hline Kashiwazaki & 81 & 0.3 & - & - & - & - \\
\hline Kashiwazaki & 82 & 0.7 & - & - & - & - \\
\hline Kashiwazaki & 83 & 1.1 & 3.0 & - & 8.9 & - \\
\hline Kashiwazaki & 84 & 1.0 & - & - & - & - \\
\hline
\end{tabular}


1 Examination of the Correlation Between Tectonic Landforms and Shallow...

Table 1.1 (continued)

\begin{tabular}{|c|c|c|c|c|c|c|}
\hline Site & ID & This study & RGAF (1991) & Geology & Gravity & Seismicity \\
\hline Kashiwazaki & 85 & 1.0 & - & - & - & - \\
\hline Kashiwazaki & 86 & 0.5 & - & 1.8 & - & - \\
\hline Kashiwazaki & 87 & 0.2 & - & - & - & - \\
\hline Kashiwazaki & 88 & 7.6 & - & 12.2 & 12.2 & - \\
\hline Kashiwazaki & 89 & 2.2 & - & - & - & - \\
\hline Kashiwazaki & 90 & 3.3 & - & - & - & - \\
\hline Kashiwazaki & 91 & 13.3 & - & - & - & 20.2 \\
\hline Kashiwazaki & 92 & 2.7 & 5.0 & 5.8 & 5.4 & - \\
\hline Kashiwazaki & 93 & 0.8 & - & - & - & - \\
\hline Kashiwazaki & 94 & 1.3 & - & 4.4 & - & - \\
\hline Kashiwazaki & 95 & 2.9 & - & 6.7 & - & - \\
\hline Hamaoka & 96 & 1.2 & - & - & - & - \\
\hline Hamaoka & 97 & 1.6 & - & - & - & - \\
\hline Hamaoka & 98 & 0.6 & - & - & - & - \\
\hline Hamaoka & 99 & 0.3 & - & - & - & - \\
\hline Hamaoka & 100 & 0.7 & - & - & - & - \\
\hline Hamaoka & 101 & 1.0 & 2.0 & - & - & - \\
\hline Hamaoka & 102 & 1.3 & 3.0 & - & - & - \\
\hline Hamaoka & 103 & 0.7 & - & - & - & - \\
\hline Hamaoka & 104 & 0.5 & - & - & - & - \\
\hline Hamaoka & 105 & 1.9 & 3.0 & - & - & - \\
\hline Hamaoka & 106 & 1.5 & 2.0 & - & - & - \\
\hline Hamaoka & 107 & 0.8 & 1.0 & - & - & - \\
\hline Hamaoka & 108 & 1.9 & - & - & - & - \\
\hline Shika & 109 & 0.5 & - & - & - & - \\
\hline Shika & 110 & 4.3 & 2.0 & 7.4 & - & - \\
\hline Shika & 111 & 2.3 & - & - & - & - \\
\hline Shika & 112 & 1.6 & - & - & - & - \\
\hline Shika & 113 & 2.6 & - & - & - & 6.4 \\
\hline Shika & 114 & 1.5 & - & - & - & - \\
\hline Shika & 115 & 1.3 & - & - & - & - \\
\hline Shika & 116 & 1.1 & - & - & - & 2.8 \\
\hline Shika & 117 & 1.5 & - & - & - & - \\
\hline Shika & 118 & 3.4 & - & - & - & 4.6 \\
\hline Shika & 119 & 5.7 & - & - & - & - \\
\hline Shika & 120 & 3.9 & 3.0 & 6.2 & - & - \\
\hline Shika & 121 & 6.3 & 2.0 & - & - & - \\
\hline Shika & 122 & 2.8 & - & - & - & - \\
\hline Shika & 123 & 1.3 & - & - & - & - \\
\hline Shika & 124 & 4.7 & 4.0 & 7.4 & - & - \\
\hline Shika & 125 & 1.5 & - & - & - & - \\
\hline Shika & 126 & 3.6 & - & - & - & - \\
\hline
\end{tabular}


Table 1.1 (continued)

\begin{tabular}{|c|c|c|c|c|c|c|}
\hline Site & ID & This study & RGAF (1991) & Geology & Gravity & Seismicity \\
\hline Shika & 127 & 1.0 & 2.0 & - & - & - \\
\hline Shika & 128 & 1.1 & - & - & - & - \\
\hline Shika & 129 & 1.9 & 3.0 & - & - & - \\
\hline Shika & 130 & 3.8 & 3.0 & 24.6 & 24.6 & - \\
\hline Shika & 131 & 3.7 & 9.0 & 24.6 & 24.6 & - \\
\hline Shika & 132 & 33.3 & 45.0 & 50.2 & 50.2 & - \\
\hline Tsuruga & 133 & 2.5 & 12.0 & 11.6 & - & - \\
\hline Tsuruga & 134 & 7.0 & - & - & 9.6 & - \\
\hline Tsuruga & 135 & 5.7 & 10.0 & 7.2 & - & - \\
\hline Tsuruga & 136 & 0.5 & - & - & - & - \\
\hline Tsuruga & 137 & 8.7 & 13.0 & - & - & - \\
\hline Tsuruga & 138 & 5.0 & - & - & - & - \\
\hline Tsuruga & 139 & 2.0 & - & - & 4.4 & - \\
\hline Tsuruga & 140 & 3.2 & - & - & 11.7 & - \\
\hline Tsuruga & 141 & 23.4 & 37.0 & 33.9 & 35.6 & - \\
\hline Tsuruga & 142 & 1.8 & - & - & - & - \\
\hline Tsuruga & 143 & 1.0 & - & - & - & - \\
\hline Tsuruga & 144 & 12.9 & 4.0 & - & 18.1 & - \\
\hline Tsuruga & 145 & 4.4 & - & - & - & - \\
\hline Tsuruga & 146 & 2.3 & - & - & - & - \\
\hline Tsuruga & 147 & 3.5 & - & - & - & - \\
\hline Tsuruga & 148 & 1.2 & - & - & - & - \\
\hline Tsuruga & 149 & 6.5 & 13.0 & 9.6 & 12.2 & - \\
\hline Tsuruga & 150 & 13.3 & - & - & - & - \\
\hline Tsuruga & 151 & 3.8 & - & - & - & - \\
\hline Tsuruga & 152 & 7.0 & 9.0 & - & - & - \\
\hline Tsuruga & 153 & 4.3 & - & - & - & - \\
\hline Tsuruga & 154 & 6.2 & 11.0 & - & - & - \\
\hline Tsuruga & 155 & 8.6 & - & - & - & - \\
\hline Tsuruga & 156 & 4.4 & 6.0 & - & - & - \\
\hline Tsuruga & 157 & 4.5 & 25.0 & 8.5 & - & - \\
\hline Tsuruga & 158 & 2.1 & - & - & - & - \\
\hline Tsuruga & 159 & 2.8 & 25.0 & 5.1 & - & - \\
\hline Tsuruga & 160 & 6.9 & 7.0 & - & 18.5 & - \\
\hline Tsuruga & 161 & 3.6 & 7.0 & - & - & - \\
\hline Tsuruga & 162 & 2.5 & - & 8.0 & - & - \\
\hline Tsuruga & 163 & 2.4 & 3.0 & - & - & - \\
\hline Tsuruga & 164 & 2.4 & - & - & - & - \\
\hline Tsuruga & 165 & 1.2 & - & - & - & - \\
\hline Tsuruga & 166 & 0.9 & - & - & - & - \\
\hline Tsuruga & 167 & 4.6 & - & - & - & - \\
\hline Tsuruga & 168 & 6.7 & 4.0 & - & - & - \\
\hline
\end{tabular}


1 Examination of the Correlation Between Tectonic Landforms and Shallow...

Table 1.1 (continued)

\begin{tabular}{|c|c|c|c|c|c|c|}
\hline Site & ID & This study & RGAF (1991) & Geology & Gravity & Seismicity \\
\hline Tsuruga & 169 & 3.0 & - & - & - & - \\
\hline Tsuruga & 170 & 2.3 & - & - & - & - \\
\hline Tsuruga & 171 & 1.8 & - & - & - & - \\
\hline Tsuruga & 172 & 1.6 & - & - & - & - \\
\hline Tsuruga & 173 & 5.3 & 6.0 & - & - & - \\
\hline Tsuruga & 174 & 2.5 & - & - & - & - \\
\hline Tsuruga & 175 & 1.9 & - & 2.6 & - & - \\
\hline Tsuruga & 176 & 5.7 & 10.0 & - & - & - \\
\hline Tsuruga & 177 & 8.0 & 7.0 & - & - & - \\
\hline Tsuruga & 178 & 1.5 & 10.0 & - & - & - \\
\hline Tsuruga & 179 & 14.8 & 15.0 & 18.9 & - & - \\
\hline Tsuruga & 180 & 17.5 & 9.0 & 20.9 & - & - \\
\hline Tsuruga & 181 & 0.4 & - & - & - & - \\
\hline Tsuruga & 182 & 2.2 & - & - & - & - \\
\hline Tsuruga & 183 & 3.1 & - & - & - & - \\
\hline Tsuruga & 184 & 0.3 & - & - & - & - \\
\hline Tsuruga & 185 & 8.0 & - & - & - & 11.6 \\
\hline Tsuruga & 186 & 2.5 & - & - & - & - \\
\hline Tsuruga & 187 & 1.3 & - & - & - & - \\
\hline Tsuruga & 188 & 2.2 & - & - & - & - \\
\hline Tsuruga & 189 & 3.9 & - & - & - & - \\
\hline Tsuruga & 190 & 9.8 & - & - & - & - \\
\hline Tsuruga & 191 & 2.1 & - & - & - & - \\
\hline Tsuruga & 192 & 4.4 & - & 4.9 & - & - \\
\hline Tsuruga & 193 & 1.4 & - & - & - & - \\
\hline Tsuruga & 194 & 1.9 & - & - & - & - \\
\hline Tsuruga & 195 & 2.7 & - & 3.3 & - & - \\
\hline Tsuruga & 196 & 23.5 & - & 28.1 & 27.5 & - \\
\hline Tsuruga & 197 & 3.8 & - & - & - & - \\
\hline Tsuruga & 198 & 8.7 & - & 13.9 & 16.7 & - \\
\hline Tsuruga & 199 & 14.4 & - & - & 15.6 & - \\
\hline Tsuruga & 200 & 18.1 & 15.0 & 21.0 & 31.8 & - \\
\hline Tsuruga & 201 & 2.6 & - & - & - & - \\
\hline Tsuruga & 202 & 7.9 & - & - & 16.0 & - \\
\hline Tsuruga & 203 & 1.8 & - & - & - & - \\
\hline Tsuruga & 204 & 1.4 & 30.0 & 14.0 & - & - \\
\hline Tsuruga & 205 & 2.1 & - & - & 9.3 & - \\
\hline Tsuruga & 206 & 13.7 & - & - & 17.5 & - \\
\hline Tsuruga & 207 & 1.5 & - & - & - & - \\
\hline Tsuruga & 208 & 1.1 & - & - & - & - \\
\hline Tsuruga & 209 & 2.3 & - & - & - & - \\
\hline Tsuruga & 210 & 0.7 & - & - & - & - \\
\hline
\end{tabular}


Table 1.1 (continued)

\begin{tabular}{|c|c|c|c|c|c|c|}
\hline Site & ID & This study & RGAF (1991) & Geology & Gravity & Seismicity \\
\hline Tsuruga & 211 & 1.5 & 2.0 & - & - & - \\
\hline Tsuruga & 212 & 4.4 & 20.0 & - & - & - \\
\hline Tsuruga & 213 & 3.0 & - & - & - & - \\
\hline Shimane & 214 & 31.7 & 22.0 & 36.8 & 40.0 & - \\
\hline Shimane & 215 & 2.1 & 2.0 & - & - & - \\
\hline Shimane & 216 & 0.8 & - & - & - & - \\
\hline Shimane & 217 & 1.3 & - & - & - & - \\
\hline Shimane & 218 & 1.8 & - & - & - & - \\
\hline Shimane & 219 & 4.7 & - & - & - & - \\
\hline Shimane & 220 & 1.5 & - & - & - & - \\
\hline Shimane & 221 & 1.4 & - & - & - & - \\
\hline Shimane & 222 & 4.0 & - & - & - & - \\
\hline Shimane & 223 & 2.7 & - & - & - & - \\
\hline Shimane & 224 & 5.2 & - & - & - & - \\
\hline Shimane & 225 & 2.7 & - & - & - & - \\
\hline Shimane & 226 & 5.0 & 6.0 & 10.6 & 15.0 & - \\
\hline Shimane & 227 & 10.8 & - & - & - & - \\
\hline Shimane & 228 & 3.0 & 3.0 & - & - & - \\
\hline Shimane & 229 & 3.3 & - & - & - & - \\
\hline Shimane & 230 & 7.2 & - & - & - & - \\
\hline Shimane & 231 & 1.4 & - & - & - & - \\
\hline Shimane & 232 & 0.8 & - & - & - & - \\
\hline Shimane & 233 & 1.3 & - & - & - & - \\
\hline Shimane & 234 & 4.9 & - & - & - & - \\
\hline Shimane & 235 & 1.7 & - & - & - & - \\
\hline Shimane & 236 & 2.2 & - & - & - & - \\
\hline Ikata & 237 & 2.4 & 4.0 & 6.8 & - & - \\
\hline Genkai & 238 & 6.6 & - & 12.5 & - & - \\
\hline Genkai & 239 & 1.4 & 2.0 & - & - & - \\
\hline Genkai & 240 & 3.0 & 1.0 & - & - & - \\
\hline Genkai & 241 & 3.8 & 6.0 & - & - & - \\
\hline Genkai & 242 & 9.2 & - & - & - & - \\
\hline Genkai & 243 & 3.1 & - & 12.5 & - & - \\
\hline Genkai & 244 & 2.8 & - & 11.3 & - & - \\
\hline Genkai & 245 & 4.1 & - & 8.1 & - & - \\
\hline Sendai & 246 & 9.9 & - & 17.8 & 29.8 & - \\
\hline Sendai & 247 & 5.6 & - & - & - & - \\
\hline Sendai & 248 & 11.6 & 14.0 & 14.5 & 14.5 & - \\
\hline Sendai & 249 & 9.2 & - & 11.1 & 13.3 & - \\
\hline
\end{tabular}

ID corresponds to the top figure in Fig. 1.1 
length. Attribute data such as fault slip type, certainty level, and tectonic landforms recognized from aerial photograph analysis are provided in GIS; these digital GIS data will be published via the Internet in the near future.

The geological map used in this study was the "Seamless Geological Map of Japan at a scale of 1:200,000 DVD edition" published by the Geological Survey of Japan [6]. Figure 1.2 shows the composite maps of the study areas superimposed on the fault lines of the top section of Fig. 1.1. The color legend of the geological map is the same as that of the "Seamless Geological Map," but is omitted here due lack of adequate space to include the 387 classifications. Please refer to the original legend. We focused on the correspondence between active surface faults and geological boundaries in Fig. 1.2.

The Bouguer gravity anomaly datasets were taken from the "Gravity CD-ROM of Japan, Ver.2" published by the Geological Survey of Japan [7]. We selected an assumed density of $2.67 \mathrm{~g} / \mathrm{cm}^{3}$ and applied 4-200 km band-pass filter processing to eliminate the effects of long wavelengths due to plate subduction. The contour interval in the bottom left section of Fig. 1.1 is $1 \mathrm{mgal}$.

The seismicity data for the bottom right sections of Fig. 1.1 were taken from the Japan Meteorological Agency's integrated hypocenter database. Data used were from between 1987 and 2011, to maximize accuracy of depth. We selected earthquakes with depths $\leq 20 \mathrm{~km}$, within the seismogenic layer of the upper crust, as our focus was on intraplate earthquakes.

The distribution of active faults (top section of Fig. 1.1) was superimposed on the geological map (Fig. 1.2), the gravity anomaly contours (bottom left section of Fig. 1.1), and the shallow seismicity map (bottom right section of Fig. 1.1) to estimate the length of subsurface earthquake faults according to our selected criteria.

\subsection{Analysis Methods}

The superimposed GIS datasets were visually compared to estimate the length of the subsurface earthquake faults, particularly the extension of short faults on the surface and connections between neighboring faults. Subjectivity is inevitable in visual observation, but in order to be as objective as possible, we applied the following general conceptual criteria.

Figure 1.3 (a) is a schematic diagram detailing how to judge the correspondence between active faults identified by aerial photograph analysis and geological boundaries in the geological map. Attention was paid to the accuracy of these maps because of the map scale difference. If the surface fault line (solid line) matches the location and strike of the geological boundary and the latter is longer, the length of the subsurface earthquake fault is estimated from the length of a series of geological boundaries (dashed line).

Figure 1.3 (b) shows a schematic model for assessing the correspondence between active faults identified by aerial photograph analysis and gravity anomaly data. If the surface fault line is situated in an area of dense contour line distribution (where a change in subsurface structure is interpreted), the length of the subsurface 
T. Kumamoto et al.
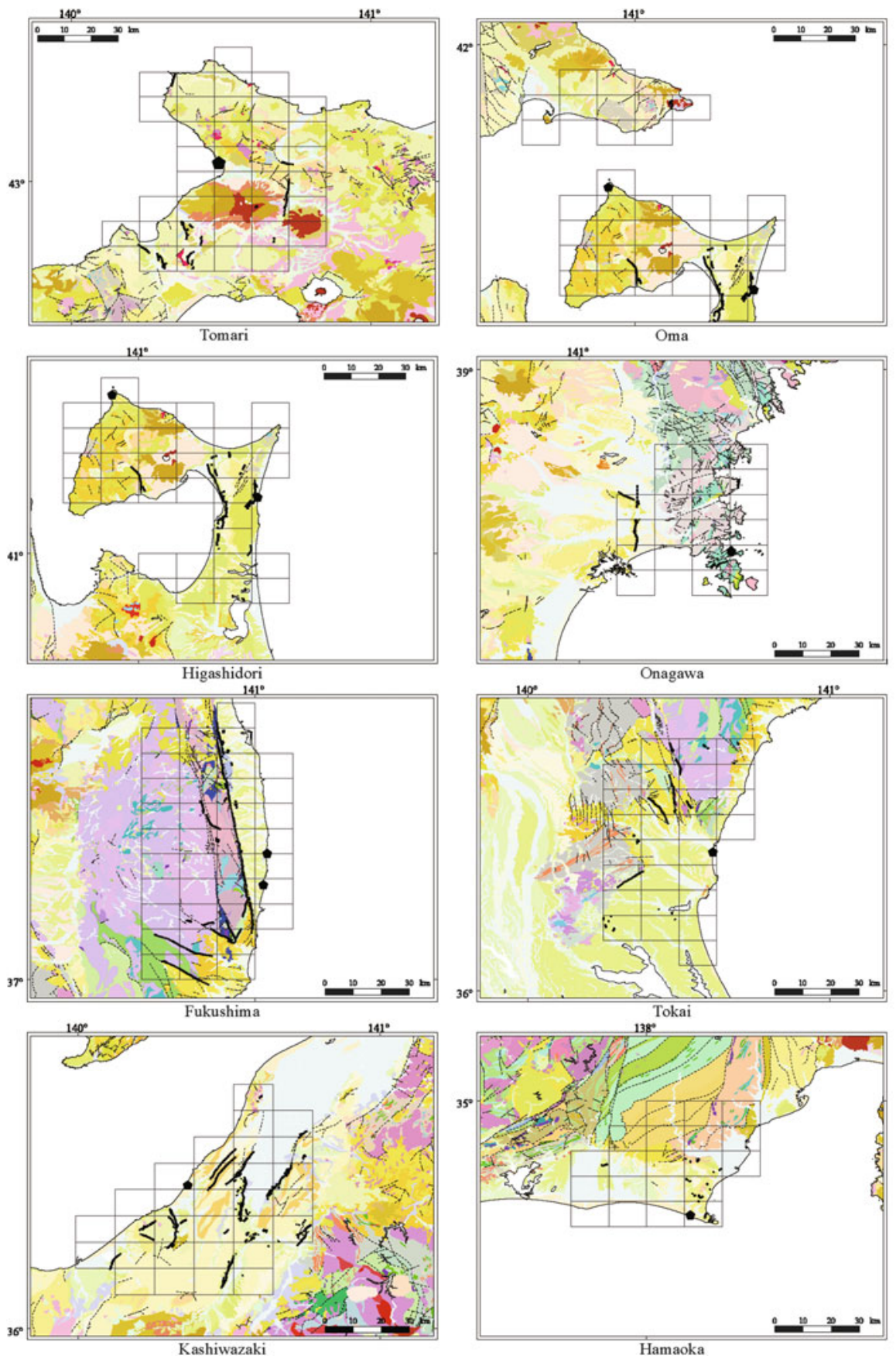

Fig. 1.2 (continued) 

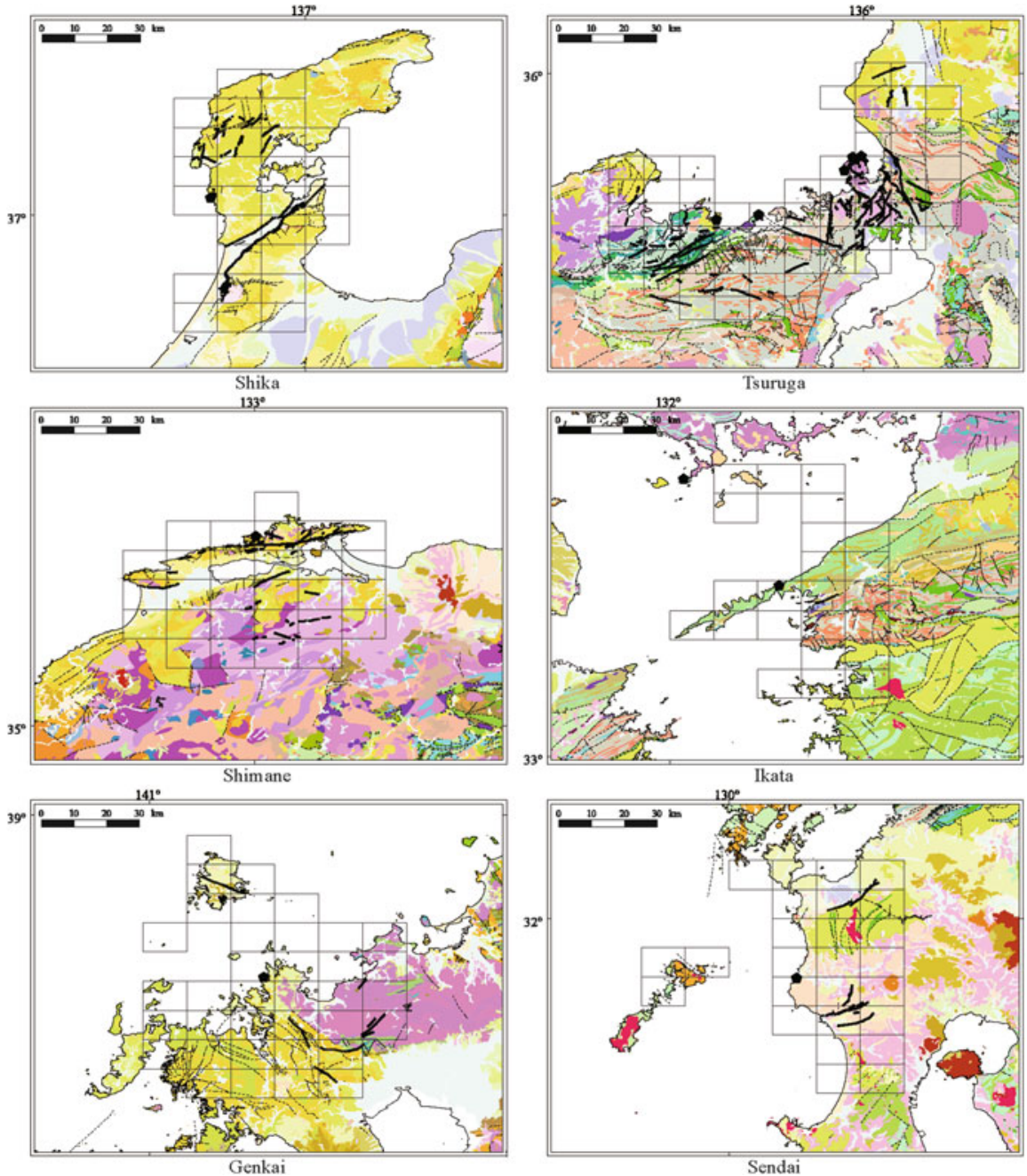

Fig. 1.2 Geological map (GSJ [6]) of 14 subjected areas overlaid with distribution of active faults of this study

earthquake fault (solid line) is estimated from the length of a portion of the dense contour line distribution (dashed line).

Figure 1.3 (c) shows a schematic diagram for determining the correspondence between active faults identified by aerial photograph analysis and seismicity data. If the surface fault line (solid line) is situated in an area with a dense distribution of seismicity, the length of the subsurface earthquake fault is estimated from the length of a portion of a series of seismicity data (dashed line). 
Fig. 1.3 Schematic diagram how to judge the correspondence between surface active fault (solid line) and estimated subsurface earthquake fault (dashed line). Top, geological map; middle, gravity anomaly contour; bottom, seismicity
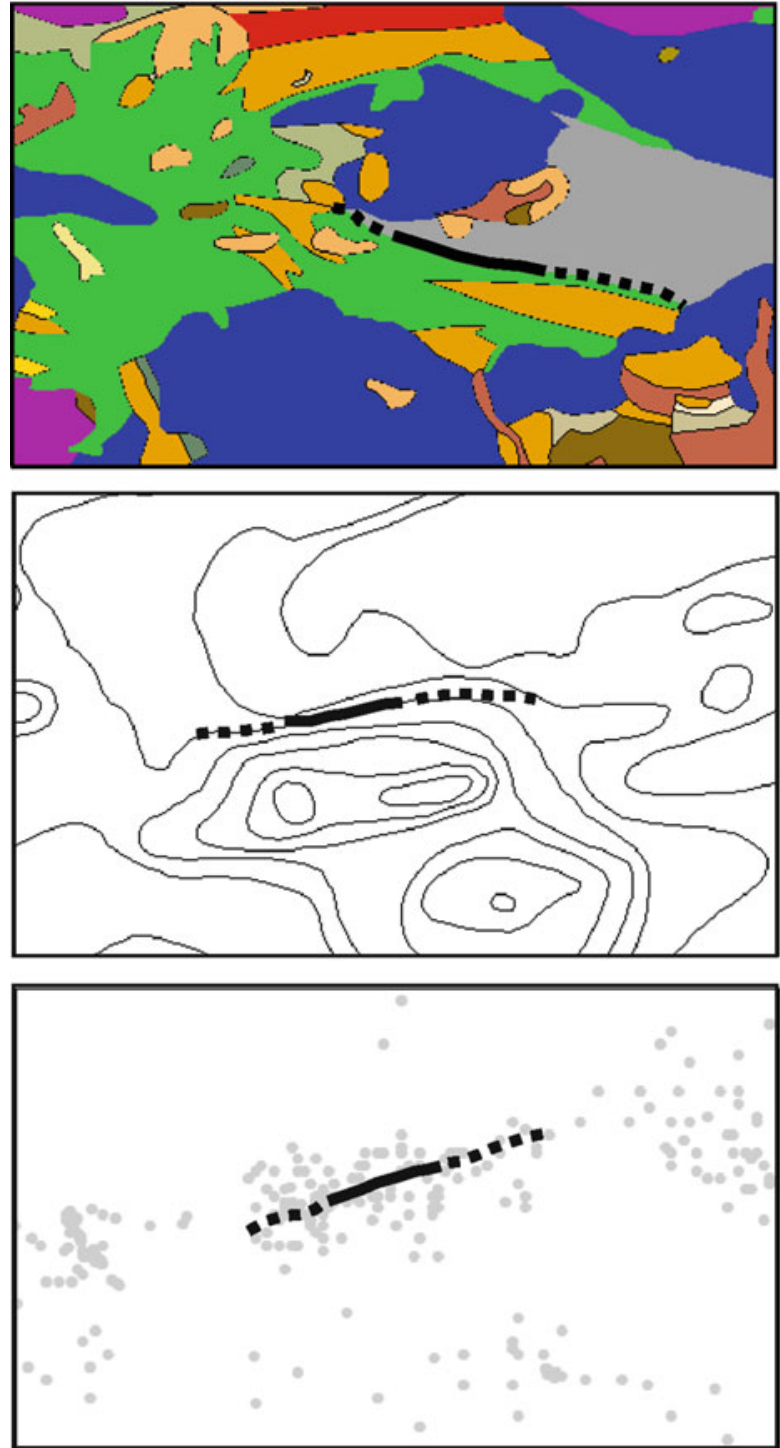

\subsection{Results and Discussion}

Total 230 active faults with $10 \mathrm{~km}$ or shorter length in Table 1.1 were subjects in discussion since these faults were excluded from the National Seismic Hazard Maps for Japan by HERP. Among these, 79 faults showed an increase in subsurface length due to linkages with neighboring faults, and the remaining 151 showed no clear correspondence. Table 1.1 shows the identification in Fig. 1.1, the lengths of 
the surface faults in this study, the lengths in of the faults in the "Active Fault Book," and the estimated lengths in this study from comparisons with the geological map, gravity anomaly contour data, and seismicity data.

The results of this study indicate that the average ratio and standard deviation between the lengths of active faults estimated on the surface and the subsurface is 7.1 and 7.3 for the geologic data, 8.4 and 4.2 for the gravity data, and 4.7 and 3.3 for the seismicity data, respectively. Although the variances are large, still much attention should be paid to this surface and subsurface structural relation to compensate for small amount of surface displacement due to short active faults. In addition, this new approach might effect the so-called " $5 \mathrm{~km}$ rule" (Matsuda [2]) for grouping and linking active fault strands on the distribution maps since neighboring faults on surface with $5 \mathrm{~km}$ or longer gap/step may become connected if subsurface structures show a series of continuity.

Figure 1.4 shows an example of the relationships between the lengths of the surface fault determined by aerial photograph analysis and the estimated subsurface fault lengths for the three datasets in Table 1.1. This figure shows that (1) the estimated length of the subsurface fault is longer than the length of the surface fault, (2) the variance increases if the surface fault length shortens, (3) there is no clear correlation between surface and subsurface fault length for those faults with $10 \mathrm{~km}$ or shorter surface lengths, and (4) the maximum estimated subsurface fault length is approximately $30 \mathrm{~km}$, that is, twice of seismogenic layer (upper crust). This indicates that faults with short surface length compared to the width of seismogenic layer still have the potential to produce large earthquakes. Though the potential earthquake magnitude of active faults with short surface length cannot be estimated solely by the surface fault length, Fig. 1.4 shows some clues of maximum length of

Fig. 1.4 Relation between the length of surface fault from aerial photograph analysis and estimated subsurface fault length among three subsurface datasets in Table 1.1

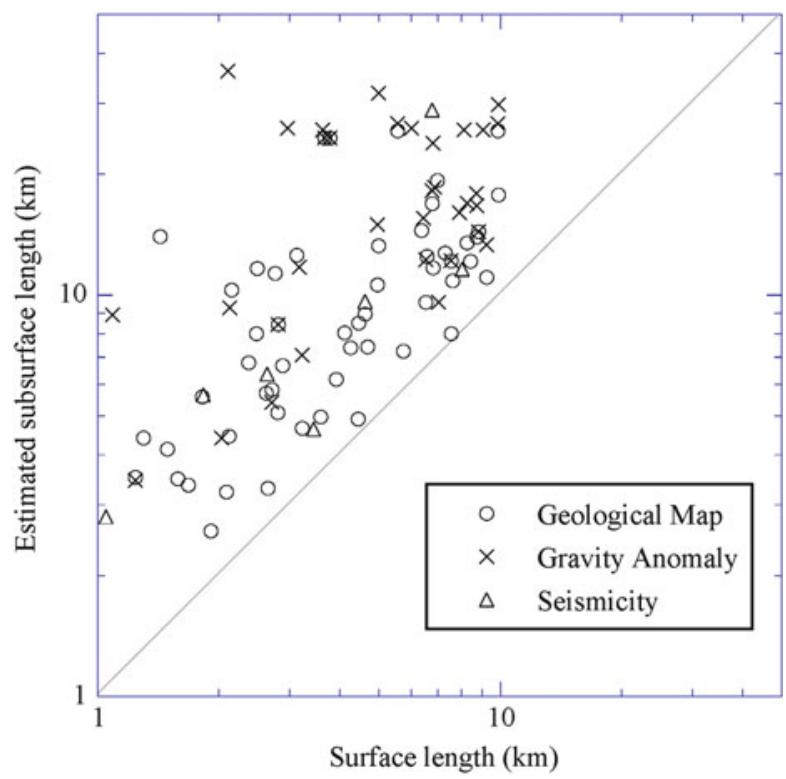


subsurface fault of $30 \mathrm{~km}$ which might relate to both the width of seismogenic layer and the aspect ratio of fault plane.

\subsection{Future Challenges}

Because aerial photographs were the primary data source for determining surface faults in this study, the study was limited to onshore active faults; no offshore active faults were considered. However, the extension of onshore faults offshore is crucial for seismic hazard assessments for nuclear power plants in Japan. An example is the Tomari nuclear power plant in Hokkaido, where the possibility of extension and linkage of the $32 \mathrm{~km}$ long onshore Kuromatsunai fault system to neighboring offshore faults results in a total fault length of $164 \mathrm{~km}$ (Asahi newspaper, 2012/3/9).

Nakata and Goto [8] demonstrated a new method for recognizing offshore faults by applying digital bathymetry data to create stereoscopic figures resulting in a seamless connection with onshore faults. It is important to develop surface and subsurface datasets for active faults both onshore and offshore for nuclear power plant seismic hazard assessments and to assess the potential of future earthquakes using multiple integrated data sources.

Acknowledgement This work is supported by Japan Nuclear Energy Safety Organization (20082011) and partly Grant-in-Aid for Scientific Research (21510191).

Open Access This chapter is distributed under the terms of the Creative Commons Attribution Noncommercial License, which permits any noncommercial use, distribution, and reproduction in any medium, provided the original author(s) and source are credited.

\section{References}

1. HERP (2010) Method of long-term evaluation of active fault (preliminary version) (in Japanese). http://www.jishin.go.jp/main/choukihyoka/katsu_hyokashuho/101125katsu_ hyokashuho.pdf

2. Matsuda T (1990) Seismic zoning map of Japanese islands, with maximum magnitudes derived from active fault data. Bull Earthq Res Inst 65:289-319

3. Geospatial Information Authority of Japan (2012) Guide for use of active fault map in urban area (in Japanese). http://www.gsi.go.jp/common/000096698.pdf

4. Research Group for Active Faults of Japan (1991) Active faults in Japan - sheet maps and inventories, Revised edn (in Japanese). University of Tokyo Press, Tokyo

5. Nakata T, Imaizumi T (eds) (2002) Digital active fault map of Japan (in Japanese). University of Tokyo Press, Tokyo

6. Geological Survey of Japan (2009) Seamless geological map of Japan at a scale of 1:200,000 DVD edition (in Japanese), GSJ, Tsukuba

7. Geological Survey of Japan (2004) Gravity CD-ROM of Japan, Ver.2 (in Japanese), GSJ, Tsukuba

8. Nakata T, Goto H (2010) Active faults along the Nankai trough deduced from detailed digital bathymetry data (in Japanese). Kagaku 80:852-857 